\title{
PREVALENCE OF BOVINE VIRAL DIARRHOEA VIRUS IN CATTLE FARMS IN HUNGARY
}

\author{
Ágnes SZABÁRA ${ }^{1 *}$, Zsolt LANG ${ }^{2}$, József FÖLDI ${ }^{3}$, Ákos HorNYÁK ${ }^{4}$, Tamás ABONYI ${ }^{4}$ \\ and László ÓZSVÁRI ${ }^{1}$ \\ ${ }^{1}$ Department of State Veterinary Medicine and Agricultural Economics and ${ }^{2}$ Department \\ of Biomathematics and Informatics, Faculty of Veterinary Science, Szent István University, \\ István u. 2, H-1078 Budapest, Hungary; ${ }^{3}$ Euvet Ltd., Gödöllö, Hungary; ${ }^{4}$ National Food \\ Chain Safety Office, Veterinary Diagnostic Directorate, Budapest, Hungary
}

(Received 1 November 2015; accepted 4 May 2016)

A study was performed to survey the virological prevalence of bovine viral diarrhoea (BVD) virus (BVDV) in cattle herds in Hungary between 2008 and 2012. A total of 40,413 samples for BVDV detection and 24,547 samples for antibody testing were collected from 3,247 herds (570,524 animals), thus representing approximately $75 \%$ of the cattle population in Hungary. Retrospective Bayesian analysis demonstrated that (1) the herd-level true virus prevalence was $12.4 \%$, (2) the mean individual (within-herd) true virus prevalence was $7.2 \%$ in the herds having at least one virus-positive animal and $0.89 \%$ for all investigated herds with a mean apparent prevalence of $1.15 \%$ for the same population. This is the first study about BVDV prevalence in Hungary.

Key words: Bayesian model, true virological prevalence, herd-level prevalence, within-herd (individual) prevalence

Bovine viral diarrhoea virus (BVDV) has a prominent importance among the infectious agents affecting cattle, due to its direct (production losses) and indirect (trade restrictions) effects on the industry (Houe, 2003). The economic loss attributable to BVDV was estimated to be $€ 4.11$ million for the national cattle herd of Hungary in 2013, i.e. $€ 12.6$ yearly per average cow. An acute BVDV outbreak is estimated to cause $€ 155,000$ damage for a dairy farm with 1,000 cows, while the same farm suffers a yearly loss of about $€ 10,000$ due to chronic subclinical infection. These expenses reflect the income increase that could be achieved per year through the eradication of bovine viral diarrhoea (BVD) and, thus, may serve as a basis for cost-benefit analyses (Szabára and Ózsvári, 2014).

A number of European countries and regions are already free of BVD (Finland, Norway, Sweden, Denmark, Shetland Islands) or are implementing a compulsory (Austria, Germany, Ireland, Scotland and Switzerland) or voluntary (Brittany in France, Lecco and Como provinces in Italy, The Netherlands) eradi-

\footnotetext{
*Corresponding author; E-mail: szabara.agnes@aotk.szie.hu; Phone: 0036 (1) 478-4100
} 
cation programme. BVD-free status is an increasing requirement for international trade of cattle both within the EU and for countries exporting to the international zone (Cowley et al., 2012; Szabára et al., 2013). An early and indispensable step of a national eradication programme should be screening for and culling persistently infected (PI) animals in order to reduce the risk of new (clinical) outbreaks and virus transmission.

Up to now, the information available on BVDV prevalence in Hungary has been fairly limited, either restricted to a certain region of the country (Kudron, 1999) or representing large farms only (Kővágó et al., 2015), and it involved exclusively serological prevalence data, i.e. no data about virus prevalence have been published.

The aim of the present study was to estimate the true prevalence $(\mathrm{P})$ of BVDV in cattle herds by Bayesian modelling and using the database of the national reference laboratory (Veterinary Diagnostic Directorate, National Food Chain Safety Office - VDD) in Hungary during a five-year period.

\section{Materials and methods}

\section{Laboratory methods $-B V D$ virus detection}

BVD whole virus or a component thereof was detected in the samples using any of the following techniques: antigen-capture ELISA $(n=19,495 ; 48 \%)$, virus isolation (VI: $\mathrm{n}=13,288 ; 33 \%$ ), quantitative real-time reverse transcription polymerase chain reaction (qRT-PCR: $\mathrm{n}=7,630 ; 19 \%$ ).

The antigen-capture ELISA was a commercially available kit, IDEXX BVDV Ag/Serum Plus (IDEXX, Laboratories, Inc., Liebefeld-Bern, Switzerland), and was used according to the manufacturer's instructions.

VI was performed on bovine kidney monolayer cell cultures through three passages. Presence of non-cytopathogenic BVDV strains was tested by a final immune-labelling step using the above antigen-capture ELISA from tissue culture supernatant.

The qRT-PCR (5' exonuclease assay, TaqMan) was developed by the Virology Laboratory of the VDD. Primers and probes were designed to attach to the 5'UTR part of the genome, a conserved region, which allows detection of a wide range of BVD viruses. Primers and probe sequences are summarised in Table 1.

VI was carried out following the method described in the OIE Manual of Diagnostic Tests and Vaccines for Terrestrial Animals - BVDV (chapter 2.4.8) and according to the laboratory protocol. Before the first application of the secondary bovine kidney cells a qRT-PCR run was performed in order to exclude Pestivirus-infected cell batches from the BVDV isolation procedures.

All antibody and virus tests result were interpreted qualitatively (positive or negative). 
Table 1

Positions refer to the genome of NADL BVDV strain (NC001461)

\begin{tabular}{|c|c|c|c|}
\hline $\begin{array}{l}\text { Primers of } \\
\text { BVDV qRT-PCR }\end{array}$ & Sequence $5^{\prime}-3^{\prime}$ & $\begin{array}{l}\text { Location } \\
\text { on the } \\
\text { genome }\end{array}$ & $\begin{array}{l}\text { Position } \\
\text { on the } \\
\text { genome }\end{array}$ \\
\hline Sense & GCCATRCCYTTAGTAGGACKAGC & UTR & 105 \\
\hline Antisense & CAACTCCATGTGCCATGTACAG & UTR-Npro & 394 \\
\hline Probe (sense) & $\begin{array}{c}\text { 56FAM/CCCTGAGTA/ } \\
\text { ZEN/CAGGGKAGTCGTCARTGGTTC/31ABkFQ }\end{array}$ & UTR & 175 \\
\hline
\end{tabular}

\section{The database}

The data used in the analysis were obtained from two databases of the National Food Chain Safety Office, Hungary. The Veterinary Diagnostic Directorate supplied the BVDV serological and virological test results for the five-year period of 2008-2012, including information about the origin of the samples and the test methods. The herd-level cattle population data were collected from the National Cattle Farming Database, Hungary.

According to the Hungarian Central Statistical Office, the cattle population in Hungary (on 1 December 2012) was 753,000, the number of cattle owner private farmers was 19,800 , and the number of companies was 1,016 . Our samples were collected from 3,247 different herds, thus representing $15.6 \%$ of the cattle owners. Considering the total population of the investigated herds in 2012 $(n=570,524)$, our study dataset represented approximately $75 \%$ of the cattle population in Hungary. Median herd size of the farms that provided samples for virus detection was 25 cattle per herd.

The samples were submitted for laboratory examination based on the farms' request; however, the purpose of testing was mainly herd screening for BVDV or animal trade. The sample types were whole blood treated with EDTA for export tests, fetus, placenta and maternal blood in abortions, whole blood treated with EDTA for herd screening, organs from dead animals, and semen samples for artificial insemination. Serum samples were used for BVDV antibody detection by virus neutralisation test. Whole blood samples treated with EDTA were used for VI, antigen detection, and nucleic acid amplification.

The farms which sent samples did not provide any information about the age of the selected animals, the BVD status of the examined herds (free of BVD or infected: seropositive and infected with BVDV or seropositive and free of BVDV), and vaccination. The majority of the samples for virus testing were taken for international trade purposes from cattle presumed to be younger than 24 months of age. 


\section{Statistical analysis}

Two Bayesian models were developed, including all the parameters and their prior distributions as introduced below. The models were estimated by Markov chain Monte Carlo (MCMC) method with Gibbs sampling implemented in OpenBUGS 3.2.2 started from within R 3.0.2 (R Core Team, 2013) invoking library R2OpenBUGS (Sturtz et al., 2005).

Diagnostic parameters. Sensitivity and specificity of the diagnostic tests were approximated by informative beta prior distributions with parameters assigned according to expert-elicited modes (most likely values) and 5\% quantiles (values smaller than $5 \%$ quantile have $5 \%$ probability) in the Bayesian models, as shown in Table 2. The parameters of the beta distribution were calculated with the method of Christensen et al. (2010) (section 5.1) implemented in epi.betabuster function in epiR library (Stevenson et al., 2015) of R 3.0.2 statistical software (R Core Team, 2013).

Table 2

Sensitivity (Se) and specificity (Sp) of the laboratory methods

\begin{tabular}{lcccc}
\hline & $\begin{array}{c}\mathrm{Se} \\
(\text { mode })\end{array}$ & $\begin{array}{c}\mathrm{Se} \\
(5 \% \text { quantile })\end{array}$ & $\begin{array}{c}\mathrm{Sp} \\
\text { (mode) }\end{array}$ & $\begin{array}{c}\mathrm{Sp} \\
\text { (5\% quantile) }\end{array}$ \\
\hline VI & 0.95 & 0.85 & 0.96 & 0.80 \\
ag-ELISA & 0.99 & 0.92 & 0.99 & 0.98 \\
qRT-PCR & 0.95 & 0.85 & 0.96 & 0.80 \\
\hline
\end{tabular}

Herd-level true prevalence of the virus. Farms with permanently zero probability of virus (virtually free) were distinguished from the exposed farms (likely to be infected), i.e. that might have contained infected animals in certain years. The proportion of farms exposed to virus infection was denoted by PVirHerd. Further, we introduced the probability PVirHY that a farm exposed to virus infection became really infected, i.e. the virus was present in a given year. The conditional probabilities PVirHY measured the average annual probability of recurrence of the infection in a farm. They quantified how stable and stationary the presence of infection was. The parameters PVirHerd and PVirHY were estimated indirectly by the Bayesian models. The annual herd-level true prevalence of the virus can be calculated as

$$
\mathrm{PVir}=\mathrm{PVirHY} \times \mathrm{PVirHerd}
$$

This quantity is the probability that a farm is infected in a given year. The parameters PVirHY and PVirHerd were fitted non-informative (i.e. uniform) priors.

Within-herd true prevalence of the virus. In each year individual or withinherd prevalence of infection varied randomly between farms that were infected. 
We fitted logistic normal distribution to within-herd prevalence across infected farms. This meant that prevalence was normally distributed on the logit scale. The logistic normal distribution was outlined by Frederic and Lad (2008). Withinherd prevalence was set to zero in farms that were not infected in the year.

In farms infected by the virus, within-herd virus prevalence had logistic normal distribution with mean $\mu_{\mathrm{v}}$ and standard deviation $\sigma_{\mathrm{v}}$ of the logittransformed virus prevalence.

The parameters were $\mu_{\mathrm{a}}$ and $\sigma_{\mathrm{a}}$ across farms possessing antibodies but not infected by the virus, and $\mu_{\mathrm{a}}+\beta$ and $\sigma_{\mathrm{a}}$ across farms containing both antibodies and viruses. Here $\beta$ measures the effect of presence of the virus on the prevalence of antibodies; $\exp (\beta)$ is the odds ratio of antibody appearance in an animal in a virus-infected vs. a virus-free farm.

In the Bayesian model parameters $\mu_{\mathrm{v}}, \sigma_{\mathrm{v}}, \mu_{\mathrm{a}}, \sigma_{\mathrm{a}}$ were allowed to vary independently between years. The parameter $\beta$ was held fixed through the follow-up period between 2008 and 2012 .

The parameters $\mu_{\mathrm{a}}$ and $\beta$ were fitted non-informative priors ranging from $-\infty$ to $+\infty$. The precision $\left(\sigma_{\mathrm{a}}\right)^{-2}$ was assigned non-informative prior between 0 and $+\infty$.

The model including non-informative priors fitted to individual virus prevalence parameters $\mu_{\mathrm{v}}$ and $\sigma_{\mathrm{v}}$ did not converge. The reason of divergence was most likely the very low number of positive samples. To achieve convergence we assigned non-informative prior between 0 and $+\infty$ to precision $\left(\sigma_{\mathrm{v}}\right)^{-2}$ and we set informative normal prior to $\mu_{\mathrm{v}}$ so that on the original inverse logit scale it followed logistic normal distribution with median 0.05 and $95 \%$ quantile 0.1 . The mean and standard deviation of the normal prior were obtained by elementary calculation as $\operatorname{logit}(0.05)=-2.9444$ and $(\operatorname{logit}(0.10)-\operatorname{logit}(0.05)) / 1.6449=$ 0.4543 , respectively. This prior was selected because the proportion of viruspositive samples was between $1 \%$ and $9 \%$ in each year among farms having at least one positive sample. Moreover, this prior was supported by several published data (Frey et al., 1996; Schreiber et al., 1999; Viet et al., 2004). We also carried out sensitivity analyses with median 0.1 and $95 \%$ quantiles 0.3 and 0.5 . The models converged and the resulting estimates were essentially not sensitive to the choice of informative priors within the range of parameters indicated.

Estimation of parameters. In each cycle of MCMC iteration farms exposed to virus infection were assigned randomly. Next, sensitivity (Se) and specificity (Sp) of each diagnostic test was updated. Each year farms actually infected were drawn randomly from exposed farms. Based on the obtained diagnostic parameters binomial distribution was fitted to the number of positive samples in each farm in each year as described by Hanson et al. (2003).

Selection of the reference population. The first Bayesian analysis was carried out on all farms that provided samples for antibody testing $(n=797)$. If samples for virus detection were also available from some of these farms, then they were included in the analysis, too $(\mathrm{n}=312$, see Table 3$)$. The second Bayes- 
ian model included all farms that submitted samples for virus detection $(\mathrm{n}=$ 2,758 , see Table 4). This can be regarded as a kind of sensitivity analysis of the virus prevalence estimates.

\section{Results}

A total of 24,547 samples were tested for BVDV antibodies and 40,413 samples for BVDV antigen from 3,247 herds: 316 herds (9.8\%) submitted samples both for antibody and virus test, while samples were available only for antibody test from $485(14.9 \%)$ and only for virus test from 2,446 (75.3\%) herds. Four out of these herds were bull stations (submitting 2,253 samples for antibody and 1,826 samples for virus detection in the five-year period), monitoring all breeding bulls and replacement steers regularly to check their BVD-virus free status, and thus a substantial part of these samples were taken from the same animals yearly. Therefore, the samples from the bull stations were excluded from the statistical analysis. A summary of the statistical analysis dataset is presented in Tables 3 and 4.

Herd-level and individual (within-herd) virus prevalence was determined in two models. The first one was carried out on the data of herds that submitted samples for antibody testing. The second model was extended to all herds that provided samples for virus detection. Consequently, the reference population of the first model was a subpopulation of the second one.

Table 3

Reference population of the first Bayesian model - Distribution of serum samples tested for BVD antibody and virus by time

\begin{tabular}{|c|c|c|c|c|c|}
\hline & \multirow{2}{*}{ Year } & \multicolumn{2}{|c|}{ Herds } & \multicolumn{2}{|c|}{ Samples } \\
\hline & & No. tested & No. positive ${ }^{*}$ & No. tested & No. positive \\
\hline \multirow[t]{6}{*}{ Antibody } & 2008 & 288 & 135 & 7,257 & 1,658 \\
\hline & 2009 & 278 & 134 & 4,612 & 1,464 \\
\hline & 2010 & 277 & 117 & 4,238 & 1,287 \\
\hline & 2011 & 329 & 143 & 4,224 & 804 \\
\hline & 2012 & 301 & 121 & 1,963 & 489 \\
\hline & Total & 797 & 373 & 22,294 & 5,702 \\
\hline \multirow[t]{6}{*}{ Virus } & 2008 & 66 & 6 & 1,450 & 18 \\
\hline & 2009 & 70 & 6 & 2,889 & 61 \\
\hline & 2010 & 83 & 12 & 1,666 & 47 \\
\hline & 2011 & 108 & 7 & 3,239 & 7 \\
\hline & 2012 & 168 & 15 & 3,060 & 37 \\
\hline & Total & 312 & 37 & 12,304 & 170 \\
\hline
\end{tabular}

${ }^{*}$ Number of herds with at least one positive sample 
Table 4

Reference population of the second Bayesian model - Distribution of serum samples tested for BVD virus by time

\begin{tabular}{lrcrcr}
\hline \multirow{2}{*}{ Year } & \multicolumn{2}{c}{ Herds } & & \multicolumn{2}{c}{ Samples } \\
\cline { 2 - 3 } \cline { 5 - 6 } & No. tested & No. positive $^{*}$ & & No. tested & No. positive \\
\hline 2008 & 93 & 9 & & 1,816 & 22 \\
2009 & 96 & 8 & & 3,604 & 66 \\
2010 & 137 & 20 & & 4,385 & 137 \\
2011 & 219 & 16 & & 8,069 & 21 \\
2012 & 2,550 & 72 & & 20,713 & 132 \\
Total & 2,758 & 108 & 38,587 & 378 \\
\hline
\end{tabular}

*Number of herds with at least one positive sample. Note: the samples tested for virus and presented in Table 3 are the sub-dataset of those presented in Table 4

Herd-level true prevalence, i.e. the proportion of herds with at least one BVD virus carrier animal, was $12.4 \%$ (CI95: 8.0-18.5) yearly in the whole population tested for the presence of virus (second model). In the evaluation period 41\% (CI95: 20.4-74.9) of the farms were exposed to the appearance of a BVD virus carrier animal, which means that only $59 \%$ can be regarded as constantly free. The probability of getting a virus carrier into an exposed herd is $32.9 \%$ (CI95: 15.8-54.3) yearly.

The herd-level true virus prevalence in the subpopulation of farms that submitted samples for both antibody and virus test (first model) was $11.5 \%$ (CI95: 6.7-17.7). This is quite close to the estimation for the whole population (second model). The proportion of exposed herds was 16.5\% (CI95: 8.9-27.7). The yearly probability of getting a virus carrier animal into an exposed herd was 71.9\% (CI95: 42.4-95.5). Hence, an exposed farm in the first model population became infected (a virus carrier animal appeared) approximately twice more likely than that in the second model population. This difference is most probably due to the higher density of cattle in the selected (first model) population; median farm size was 516 cattle in the first and 25 cattle in the second model population.

Within-herd (individual level) true prevalence of the virus carrier animals in the virus-positive herds and all tested herds, as well as the apparent virus prevalence are presented in Table 5.

The proportion of virus carrier animals in the virus-positive herds continuously decreased over time, except for an increase between 2011 and 2012. Neither of these changes was statistically significant (all CI95s of the differences included zero). 
Table 5

Within-herd BVD virus true prevalence in infected and all tested herds and apparent prevalence in all tested herds by Bayesian analysis

\begin{tabular}{lcccr}
\hline Year & $\begin{array}{c}\text { True P }(\%) \\
\text { in infected herds } \\
(95 \% \mathrm{CI})\end{array}$ & $\begin{array}{c}\text { True P }(\%) \\
\text { in all herds }\end{array}$ & $\begin{array}{c}\text { Apparent P (\%) } \\
\text { in all herds } \\
(95 \% \text { CI })\end{array}$ & PP diff. $^{*}$ \\
\hline 2008 & $15.8(3.1-40.1)$ & 1.96 & $1.13(0.75-1.65)$ & -0.83 \\
2009 & $7.2(3.5-11.2)$ & 0.89 & $1.20(0.80-1.67)$ & 0.31 \\
2010 & $5.5(4.1-7.3)$ & 0.68 & $2.30(1.80-2.86)$ & 1.62 \\
2011 & $3.0(1.3-5.8)$ & 0.37 & $0.40(0.27-5.60)$ & 0.03 \\
2012 & $4.5(2.7-6.8)$ & 0.56 & $0.70(0.55-8.02)$ & 0.14 \\
\hline
\end{tabular}

$\mathrm{P}=$ prevalence; ${ }^{*}$ percentage point difference

Standard deviation of the individual prevalence among the virus-positive herds was always higher than the yearly mean prevalence, which shows large heterogeneity, i.e. only 1-2 carrier cattle lived on the majority of the viruspositive farms, while a few farms had more of such animals.

\section{Discussion}

According to a research conducted in the Western Danubian region of Hungary, $95 \%$ of the large-scale dairy herds were BVDV antibody positive in 1999 (Kudron, 1999). A survey for antibody prevalence, also among large-scale dairies in Hungary, including non-vaccinated animals over 6 months of age and based on testing a small sample size (10-30 sera per herd) revealed $70.4 \%$ herdlevel apparent prevalence and $43.4 \%$ within-herd apparent prevalence (Kővágó et al., 2015).

Our retrospective Bayesian analysis demonstrated that (1) the herd-level true virus prevalence was $12.4 \%$, (2) the mean individual (within-herd) true virus prevalence through a five-year period was $7.2 \%$ in the herds having at least one virus-positive animal, $0.89 \%$ for all investigated herds with a mean apparent prevalence of $1.15 \%$ for the same population, and (3) within-herd true virus prevalence in the BVD virus carrying herds changed year by year. This is the first study about BVD virus prevalence in Hungary, so these results cannot be compared to findings obtained in Hungary earlier. It can be concluded that the herd-level true virus prevalence is much lower in Hungary than in many other EU countries. In contrast, the within-herd virus prevalence was surprisingly high. This is attributable to the low number of (large-scale) farms, where virus carrier animals are present more frequently than usual, most probably due to extensive cattle trade. 
In summary, BVDV can definitely be considered endemic in Hungary. The prevalence figures are in accordance with the data found in the literature (Cowley et al., 2012). Thus, it can be said that the obligatory BVD-free status for the transport of breeding heifers older than 1 year and of cows would effectively decrease the spread of the virus among Hungarian cattle herds. Moreover, BVDfree status should also be made mandatory for animals grazing together on common pastures. It would also be extremely helpful in preventing the spread of BVD virus if biosecurity measures (e.g. isolation) were strictly implemented in the cattle farms and if in the private contracts the buyer required the BVD-free status of breeding heifers/cows to be bought.

\section{Acknowledgements}

This study was sponsored by the Hungarian Scientific Research Fund (OTKA K108571 project) and the Research Faculty Grant 2014 of the Faculty of Veterinary Science, Szent István University. The research was supported by the 9877-3/2015/FEKUT grant of the Hungarian Ministry of Human Resources.

\section{References}

Christensen, R., Johnson, W., Branscum, A. and Hanson, T. E. (2010): Bayesian Ideas and Data Analysis: An Introduction for Scientists and Statisticians. Chapman and Hall, Boca Raton.

Cowley, D. J. B., Clegg, T. A., Doherty, M. L. and More, S. J. (2012): Bovine viral diarrhoea virus seroprevalence and vaccination usage in dairy and beef herds in the Republic of Ireland. Ir. Vet. J. 65, 16-30.

Frederic, P. and Lad, F. (2008): Two moments of the logitnormal distribution. Commun. Stat.Simul. C. 37, 1263-1269.

Frey, H. R., Flebbe, U. and Liess, B. (1996): Prävalenz und klinische Symptomatik persistenter BVDVirusinfektionen in Rinderbestanden Niedersachsens. Prakt. Tierarzt 1, 49-52.

Hanson, T. E., Johnson, W. O., Gardner, I. A. and Georgiadis, M. P. (2003): Determining the infection status of a herd. J. Agric. Biol. Environ. Stat. (JABES) 8, 469-485.

Houe, H. (2003): Economic impact of BVDV infection in dairies. Biologicals 31, 137-143.

Kővágó, Cs., Forgách, P., Szabára, Á., Mándoki, M., Hornyák, Á., Duignan, C., Pásztiné Gere, E. and Rusvai, M. (2015): Seroprevalence of bovine viral diarrhoea virus in Hungary - situation before launching an eradication campaign. Acta Vet. Hung. 63, 255-263.

Kudron, E. (1999): The change in the Western Transdanubian viral infection in cattle herds between 1972-1996 [in Hungarian, with English abstract]. Magy. Allatorvosok 121, 264-266.

R Core Team 2013 R (2013): A Language and Environment for Statistical Computing. R Foundation for Statistical Computing, Vienna, Austria. http://www.R-project.org/ Accessed 11 March 2015

Schreiber, P., Dubois, F., Dreze, F., Lacroix, N., Limbourg, B. and Coppe, P. (1999): Prevalence of bovine virus diarrhoea virus infection in Belgian white blue cattle in southern Belgium. Vet. Q. 21, 28-32.

Stevenson, M., Nunes, T., Heuer, C., Marshall, J., Sanchez, J., Thornton, R., Reiczigel, J., Robison-Cox, J., Sebastiani, P., Solymos, P., Yoshida, K. and Firestone, S. (2015): epiR: Tools 
for the Analysis of Epidemiological Data. R package version 0.9-62. http://CRAN.Rproject.org/package=epiR. Accessed: 11 March 2015.

Sturtz, S., Ligges, U. and Gelman, A. (2005): R2WinBUGS: A Package for Running WinBUGS from R. J. Statist. Software 12, 1-16.

Szabára, Á. and Ózsvári, L. (2014): Economic impacts, control and eradication of Bovine Viral Diarrhoea Virus. In: Dunay, A. (ed.) Challenges for the Agricultural Sector in Central and Eastern Europe. Agroinform Kiadó, Budapest. pp. 247-258.

Szabára, Á., Hajtós, I., Földi, J. and Ózsvári, L. (2013): Control and eradication of bovine viral diarrhoea (BVD): state veterinary and management aspects [in Hungarian, with English abstract]. Magy. Allatorvosok 135, 643-654.

Viet, A. F., Fourichon, C., Seegers, H., Jacob, C. and Guihenneuc-Jouyaux, C. (2004): A model of the spread of the bovine viral-diarrhoea virus within a dairy herd. Prev. Vet. Med. 63, 211-236. 